\title{
Electrochemical determination of tryptophan at room-temperature ionic liquid-titanium carbide nanoparticle gel modified electrode
}

\author{
Fei Li • Qing Zhang • Dawei Pan • Mingyue Lin • Qi Kang
}

Received: 11 September 2014 / Revised: 4 November 2014 / Accepted: 9 November 2014 / Published online: 30 November 2014

(C) Springer-Verlag Berlin Heidelberg 2014

\begin{abstract}
The novel gel composite, based on the ground of ionic liquid (1-butyl-3-methylimidazolium hexafluorophosphate, $\mathrm{BMIMPF}_{6}$ ) and titanium carbide (TiC) nanoparticles, was used to modify glassy carbon electrode and applied to the electrochemical determination of tryptophan (trp). The physical and electrochemical characterizations of the $\mathrm{BMIMPF}_{6}-\mathrm{TiC}$ gel modified electrode were studied in detail by scanning electron microscopy, energy dispersive X-ray spectroscopy, cyclic voltammetry, and differential pulse voltammetry methods. Due to the large specific surface area and strong adsorption property of TiC nanoparticles, as well as the good ionic conductivity and strong electrocatalytic property of BMIMPF $_{6}$, the oxidation peak current of trp at BMIMPF $_{6}-$ TiC gel modified electrode showed good linear relation with its concentrations ranging from 0.50 to $30 \mu \mathrm{mol} / \mathrm{L}$ and 30 to $500 \mu \mathrm{mol} / \mathrm{L}$, respectively. The detection limit was $0.053 \mu \mathrm{mol} / \mathrm{L}$. More importantly, the BMIMPF $_{6}-\mathrm{TiC}$ gel modified electrode had good antiinterference ability and can be successfully applied in the electrochemical determination of trp in real food samples.
\end{abstract}

\footnotetext{
F. Li $\cdot$ Q. Zhang $\cdot$ Q. Kang $(\bowtie)$

The Key Lab in Molecular and Nano-materials Probes of the Ministry of Education of China, College of Chemistry, Chemical Engineering and Materials Science, Shandong Normal University, Jinan, Shandong 250014, People's Republic of China e-mail: qikang@sdu.edu.cn

D. Pan $(\varangle) \cdot$ M. Lin

Key Laboratory of Coastal Environmental Processes and Ecological Remediation, Yantai Institute of Coastal Zone Research(YIC), Chinese Academy of Sciences(CAS), Shandong Provincial Key Laboratory of Coastal Environmental Processes, YICCAS, Yantai, Shandong 264003, People's Republic of China

e-mail: dwpan@yic.ac.cn
}

Keywords TiC nanoparticles $\cdot$ Ionic liquid $\cdot$ Tryptophan · Electrochemical characterizations $\cdot$ Electrode $\cdot$ Ionic conductivity

\section{Introduction}

In the past years, electrochemical analysis based on the selective sensors has been improved promptly [1-22] with the use of the novel materials. Room-temperature ionic liquids (RTILs) as a new material have been attracted by scientists in decade years. RTILs are ionic media resulting from the combination of organic cations and various anions; they are liquids at room-temperature and represent a new class of nonaqueous but polar solvents, which are able to dissolve many compounds [23]. They are good solvents for a wide range of inorganic and organic materials, have no appreciable vapor pressure at room-temperature, and have moderate viscosity [24]. These advantages make the ionic liquids more and more popular and widely used in electrochemical analysis [25-29].

Nanomaterials show higher electrocatalytic activity, small size, and large specific surface area, with unique physical properties as a kind of special sensing material of chemically modified electrodes [30-36]. In the past, the voltammetric sensor was developed based on nanomaterials in the presence of RTILs for drug and other important biological compound analysis [37-47]. TiC is representative transition metal carbide. It has high melting point, high thermal and electrical conductivity, high chemical stability, and catalysis activity. TiC nanoparticles not only owe the excellent characteristics of TiC block, but also have the characteristics of nanomaterials. Due to large specific surface area, good biocompatibility, good conductivity, and adsorption performance, TiC nanoparticles have been widely used in the chemical field. Zheng [48] successfully prepared a novel PANI-TiC nanocomposite through the in situ chemical oxidative 
polymerization method, in which PANI and TiC showed an excellent synergic effect. Furthermore, the PANI-TiC exhibited good electrocatalytic activity toward AA. However, the TiC nanoparticles are solid and hard to be modified electrode alone.

Trp is essential amino acid for humans and a precursor for serotonin (a neurotransmitter), melatonin (a neurohormone), and niacin. The molecular structure of trp is shown in Scheme 1. It has been implicated as a possible cause of schizophrenia in people who cannot metabolize it properly. So, many technologies have been applied to the detection of trp, such as high-performance liquid chromatography [49-52], capillary electrophoresis [53-57], fluorometric methods [58], chemiluminescence [59-63], and ultraviolet detection [64]. Although these methods have the benefits of sensitivity and accuracy, their high cost, time-consuming, and complicated operations limit their extensive application for routine trp analysis. However, electrochemical method for monitoring trp has shown promise compared to the methods above. It is well known that the electrochemical detection of trp at the unmodified electrode is not optimal owing to sluggish electron transfer processes and high over-potential [65]; so, lots of efforts have been contributed to seek the new material for electrode modification in order to promote the electron transfer and reduce the over-potential [66-78].

In this study, ground RTIL BMIMPF 6 and TiC nanoparticles to make the gel compound, which was used to modify glassy carbon electrode and applied to the electrochemical determination of trp. Due to the fact that $\mathrm{BMIMPF}_{6}-\mathrm{TiC}$ gel has large specific surface area and adsorption performance and has good electric conductivity and electric catalytic performance, the modified electrode has wide linear range, high sensitivity, low detection limit, excellent reproducibility, and good anti-interfering capability. Under the optimized conditions, the oxidation current of trp with its concentration has a good linear relationship; the detection limit of trp was $0.053 \mu \mathrm{mol} / \mathrm{L}$. This novel $\mathrm{BMIMPF}_{6}-\mathrm{TiC}$ gel modified electrode was applied for the determination of trp in real samples.

\section{Experimental}

\section{Reagents}

Trp was obtained from Shanghai SSS Reagent Co. Ltd. BMIMPF $_{6}$ was supplied by Shanghai Cheng Jie Chemical Co. Ltd. TiC nanoparticles were obtained from Nanjing Emperor Nano Material Co. Ltd. All other chemicals were of analytical reagents and used without further purification. All experiments were conducted at room-temperature, and the solutions were used in the process without nitrogen atmosphere. Deionized water (18.2 $\mathrm{M} \Omega \mathrm{cm}$ specific resistance) obtained with a Pall Cascada laboratory water system was used throughout.

A $0.05 \mathrm{~mol} / \mathrm{L}$ trp solution was prepared daily by dissolving $1.02 \mathrm{~g}$ trp in a $\mathrm{NaOH}$ solution $(0.02 \mathrm{~mol} / \mathrm{L})$ in a $100-\mathrm{mL}$ volumetric flask with ultrasonication for several minutes. More diluted solutions were prepared by serial dilutions with water.

\section{Real sample preparation}

The milk was bought from supermarket, and the urine was gained from hospital. Before usage, the milk was filtered through a $15 \sim 20 \mu \mathrm{m}$ normal filter paper. The urine and the milk were diluted five times with $0.1 \mathrm{M}$ PBS (pH 5.5) without subjecting it to any further pretreatment.

\section{Apparatus}

The morphology and elemental composition of the modified electrodes were characterized by using scanning electron microscopy (SEM Hitachi S-4800 microscope, Japan) and energy dispersive X-ray spectroscopy (EDX HORIBA EX-350), respectively. All the electrochemical experiments were performed in a conventional three-electrode cell controlled by LK2005A Electrochemical Work Station (LANLIKE Instruments, Inc.). A modified glassy carbon (GC) disk ( $3 \mathrm{~mm}$ in diameter) and a platinum foil were used as the working and counter electrodes, respectively. $\mathrm{Hg} / \mathrm{HgCl}_{2}$ reference electrode was adopted in saturated $\mathrm{KCl}$ aqueous solution.

\section{Preparation of the modified electrode}

Prior to use, GCE was polished to a mirror finish using a microcloth with $0.05 \mu \mathrm{m}$ alumina slurry, then rinsed, and ultrasonicated with deionized water. Twenty-five milligram TiC nanoparticles and $20 \mu \mathrm{L} \mathrm{BMIMPF}_{6}$ were mixed in an agate mortar grinding at least $20 \mathrm{~min}$ [79] until perfect homogeneous $\mathrm{BMIMPF}_{6}-\mathrm{TiC}$ gel was obtained. The friction between GCE and smooth slide coated with BMIMPF $_{6}-\mathrm{TiC}_{\mathrm{C}} \mathrm{el}$ composite will last at least $15 \mathrm{~min}$ and resulting in a layer of gel film on GCE surface.

\section{Electrochemical analysis procedure}

Unless otherwise stated, $0.1 \mathrm{M}$ phosphate buffer solution (PBS, pH 5.5) was used as the supporting electrolyte for trp determination. Cyclic voltammetry $(\mathrm{CV})$ and differential pulse voltammetry (DPV) methods were adopted. CV was performed under the following parameters: initial potential of $-0.2 \mathrm{~V}$, final potential of $0.6 \mathrm{~V}$, scan rate of $0.05 \mathrm{~V} / \mathrm{s}$. DPV was performed under the following parameters: initial potential of $0.5 \mathrm{~V}$, final potential of $0.9 \mathrm{~V}$, amplitude of $0.05 \mathrm{~V}$, potential 
Fig. 1 SEM micrograph of the bare GCE (a) and BMIMPF $_{6}$ TiC/GCE (b)
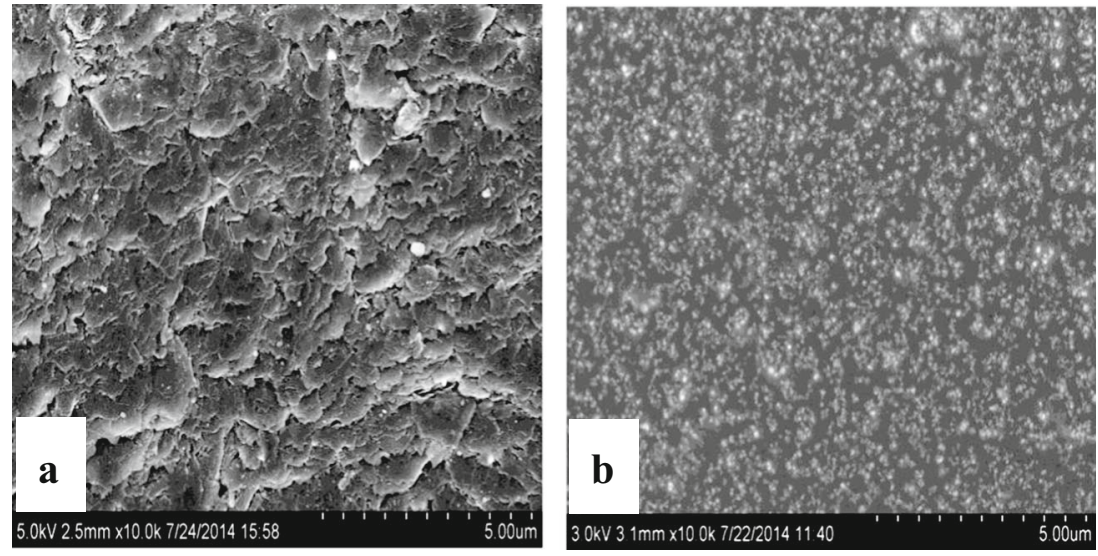

incremental of $0.01 \mathrm{~V}$, pulse width of $0.2 \mathrm{~s}$, pulse period of $0.45 \mathrm{~s}$, quiet time of $2 \mathrm{~s}$.

\section{Results and discussion}

Characterization of the $\mathrm{BMIMPF}_{6}$-TiC gel modified electrode

Figure 1 shows the surface morphologies of bare GCE (Fig. 1a) and BMIMPF 6 -TiC/GCE (Fig. 1b). As shown in Fig. 1a, the bare GCE was rough and nonuniform. Compared with Fig. 1a, Fig. 2b shows plenty of $\mathrm{TiC}$ that appeared in the $\mathrm{BMIMPF}_{6}$ film. The SEM photograph illustrated that the BMIMPF6-TiC gel was successfully modified on the surface of the GCE and has a well-defined morphology with almost uniform size and shape. In order to further prove that the BMIMPF6-TiC gel was successfully modified on the surface of the GCE, BMIMPF6-TiC/GCE was characterized by EDX (Fig. 2). The EDX result showed that strong Ti, C, F, and $\mathrm{P}$ signals were detected. Thus, Ti signal must be contributed by TiC. The source of $\mathrm{F}$ and $\mathrm{P}$ may be from the $\mathrm{BMIMPF}_{6}$. The SEM and EDX results indicated that BMIMPF$_{6}-$ TiC gel was successfully modified on the surface of the GCE.

The active surface areas of the modified electrodes were estimated according to the slope of the I $p$ versus $v^{1 / 2}$ plot for a known concentration of $\mathrm{K}_{3} \mathrm{Fe}(\mathrm{CN})_{6}$, based on the RandlesSevcik equation:

$I p=2.69 \times 10^{5} \mathrm{n}^{3 / 2} \mathrm{AD}^{1 / 2} v^{1 / 2} \mathrm{C}_{0}$

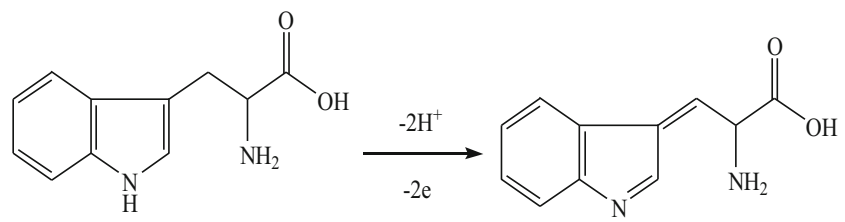

Scheme 1 Electrochemical oxidation mechanism of trp on the electrode
Ip refers to the anodic peak current. $\mathrm{n}$ is the electron transfer number. $\mathrm{A}$ is the surface area of the electrode. $\mathrm{D}$ is the diffusion coefficient. $\mathrm{C}_{0}$ is the concentration of $\mathrm{K}_{3} \mathrm{Fe}(\mathrm{CN})_{6}$, and $v$ is the scan rate. For $1.0 \mathrm{mmol} / \mathrm{L} \mathrm{K}_{3} \mathrm{Fe}(\mathrm{CN})_{6}$ in $0.10 \mathrm{~mol} / \mathrm{L} \mathrm{KCl}$ electrolyte, $\mathrm{n}$ equals 1 , and $\mathrm{D}$ is $7.6 \times$ $10^{-6} \mathrm{~cm} / \mathrm{s}$. From the slope of the $I p-v^{1 / 2}$ relation, the microscopic areas were calculated. They were 0.076 and $0.066 \mathrm{~cm}^{2}$ for $\mathrm{BMIMPF}_{6}-\mathrm{TiC} / \mathrm{GCE}$ and GCE, respectively. The results show that presence of $\mathrm{BMIMPF}_{6}-\mathrm{TiC}$ gel causes the increase of the active surface of the electrode but not very much. The improvement of the sensitivity is due to a fast electron transfer process that can occur at $\mathrm{BMIMPF}_{6}-\mathrm{TiC} / \mathrm{GCE}$.

The typical CVs for $\mathrm{BMIMPF}_{6}-\mathrm{TiC} / \mathrm{GCE}$ and bare $\mathrm{GCE}$ were recorded between -0.2 and $0.6 \mathrm{~V}$ in $1 \mathrm{mmol} / \mathrm{L} \mathrm{Fe}(\mathrm{CN})_{6}{ }^{3}$ ${ }^{-/ 4-}$ and $0.1 \mathrm{M} \mathrm{KNO}_{3}$ solution (Fig. 3). The $\mathrm{CVs}$ of the bare GCE (Fig. 3a) and BMIMPF ${ }_{6}$-TiC/GCE (Fig. 3b) showed a well-shaped reduction-oxidation (redox) peak. However, the peak-to-peak potential of $\mathrm{Fe}(\mathrm{CN})_{6}{ }^{3-/ 4-}$ at $\mathrm{BMIMPF}_{6}-\mathrm{TiC} /$ GCE is slightly wider than that at bare GCE. This may be due to the electrostatic repulsion force between the negatively charged $\mathrm{Fe}(\mathrm{CN})_{6}{ }^{3-/ 4-}$ and $\mathrm{BMIMPF}_{6}-\mathrm{TiC}$ gel. However, the peak currents of $\mathrm{Fe}(\mathrm{CN})_{6}{ }^{3-/ 4-}$ at $\mathrm{BMIMPF}_{6}$-TiC/GCE are higher than those at bare GCE, which indicated that a fast electron transfer process can occur at $\mathrm{BMIMPF}_{6}$-TiC/GCE.

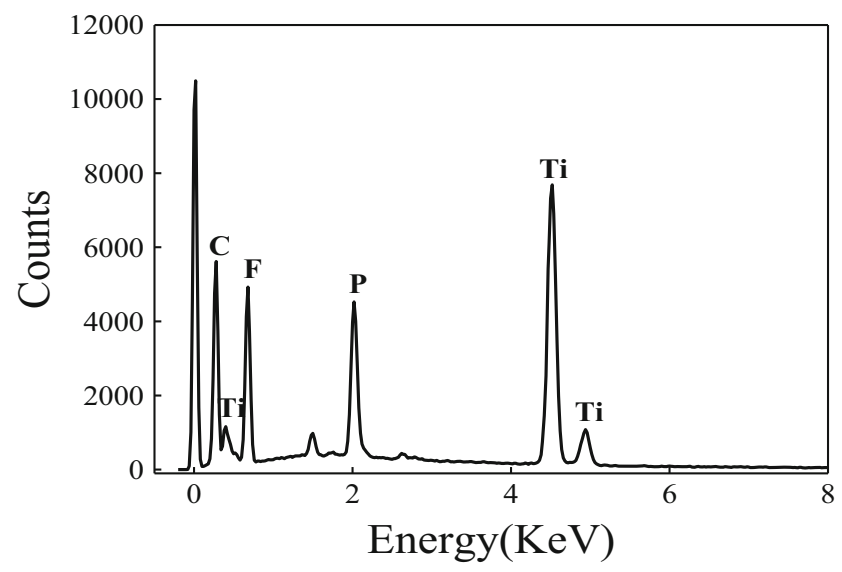

Fig. 2 EDX spectrum of $\mathrm{BMIMPF}_{6}-\mathrm{TiC} / \mathrm{GCE}$ 


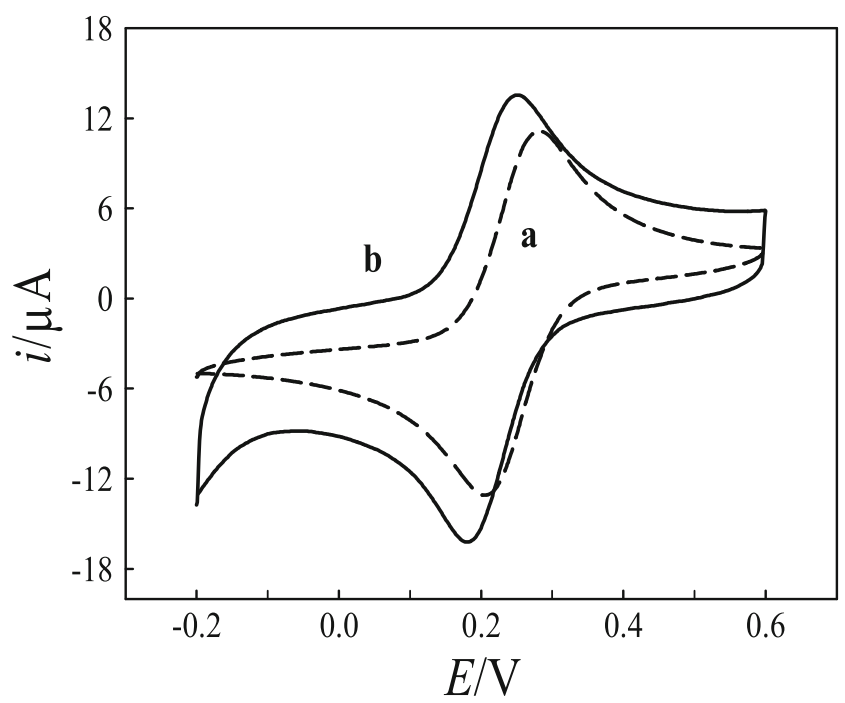

Fig. $3 \mathrm{CVs}$ of a bare GCE and $\mathbf{b} \mathrm{BMIMPF}_{6}-\mathrm{TiC} / \mathrm{GCE}$ in $1 \mathrm{mmol} / \mathrm{L}$ $\left[\mathrm{Fe}(\mathrm{CN})_{6}\right]^{3-/ 4-}$ and $0.1 \mathrm{M} \mathrm{KCl}$ solution in the potential range of -0.2 to $0.6 \mathrm{~V}$. Scan rate $50 \mathrm{mV} / \mathrm{s}$

Electrochemical behavior of trp on the $\mathrm{BMIMPF}_{6}-\mathrm{TiC}$ modified GCE

Figure 4 shows the DPVs of bare GCE (Fig. 4a) and BMIMPF $_{6}$-TiC/GCE (Fig. 4b) in 0.1-mol/L PBS solution (pH 5.5) containing $10 \mu \mathrm{mol} / \mathrm{L}$ trp. The small oxidation peak of trp was obtained at bare GCE. The peak potential of trp is $0.72 \mathrm{~V}$, and the peak current is $0.62 \mu \mathrm{A}$ (Fig. $4 \mathrm{a}$ ), while the peak potential of trp at $\mathrm{BMIMPF}_{6}-\mathrm{TiC} / \mathrm{GCE}$ is $0.68 \mathrm{~V}$ and the peak current is $3.68 \mu \mathrm{A}$ (Fig. 4b). The peak current of trp at the BMIMPF $_{6}$-TiC/GCE showed up to the fivefold improvement than that at bare GCE. As a result of the catalysis of $\mathrm{BMIMPF}_{6}$, the oxidation peak potential of trp shifted negatively. These results suggested that the $\mathrm{BMIMPF}_{6}-\mathrm{TiC}_{\mathrm{C}}$ gel not only possess strong electrocatalytic activity toward the redox

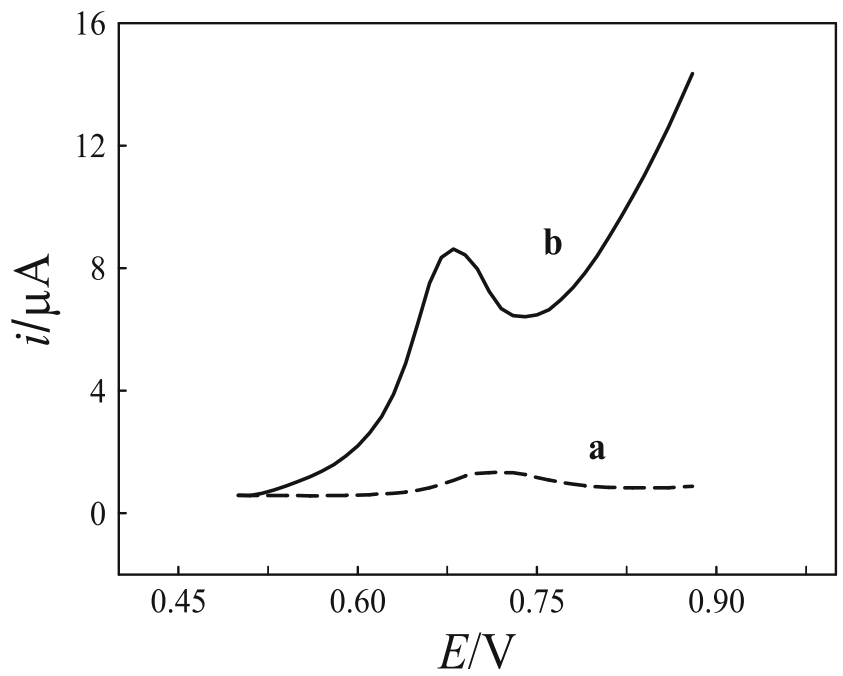

Fig. 4 DPVs of a bare GCE and $\mathbf{b} \mathrm{BMIMPF}_{6}-\mathrm{TiC} / \mathrm{GCE}$ in $0.1 \mathrm{M}$ PBS (pH 5.5) containing $10 \mu \mathrm{mol} / \mathrm{L}$ trp. Scan rate $50 \mathrm{mV} / \mathrm{s}$ reaction but also promoted the electron transfer rate on the surface of the electrode. The relationship between scan rate and the peak current of trp was also investigated. The anodic peak currents of trp were proportional to the square root of the scan rate from 5 to $100 \mathrm{mVs}^{-1}$ (Fig. 5). This result indicated that the electro-oxidation reaction of trp at $\mathrm{BMIMPF}_{6}-\mathrm{TiC} /$ GCE was a typical diffusion-controlled process.

Optimization for trp measurement on $\mathrm{BMIMPF}_{6}$-TiC/GCE

\section{Effect of the ratio of TiC nanoparticles in $B M I M P F_{6}$}

To optimize the electrocatalytic response of the $\mathrm{BMIMPF}_{6^{-}}$ $\mathrm{TiC} / \mathrm{GCE}$ for trp oxidation, the ratio of TiC nanoparticles $(\mathrm{mg})$ in $\mathrm{BMIMPF}_{6}(\mu \mathrm{L})$ was studied between 0.6 and 2 with $10 \mu \mathrm{mol} / \mathrm{L}$ trp in $0.1 \mathrm{~mol} / \mathrm{L} \mathrm{PBS} \mathrm{(pH} \mathrm{5.5).} \mathrm{The} \mathrm{largest} \mathrm{oxida-}$ tion peak current of trp is obtained at the $\mathrm{BMIMPF}_{6}-\mathrm{TiC} / \mathrm{GCE}$ incorporating TiC nanoparticles $(m / v 1.25)$ in $\mathrm{BMIMPF}_{6}$ from Fig. 6. Thus, the $\mathrm{BMIMPF}_{6}$ incorporating $\mathrm{TiC}(m / v 1.25)$ nanoparticles is selected for trp detection.

\section{Effect of $\mathrm{pH}$ values}

The $\mathrm{pH}$ value of the supporting electrolyte is an important factor that affects the voltammetric response of trp. The existing form of trp in the solution is highly affected by the $\mathrm{pH}$ values. There is a pair of unpaired electron on the nitrogen atoms in the amino group. In strong acid solution, it will combine with $\mathrm{H}^{+}$and is not conducive to the formation of free radicals of nitrogen; thus, the oxidation reaction is more difficult. When in strong alkaline solution, the $\mathrm{OH}^{-}$in aqueous solution will produce oxygen evolution reaction easily on electrode and will affect the stability of system. So, too low or too high $\mathrm{pH}$ values are not conducive to the determination of

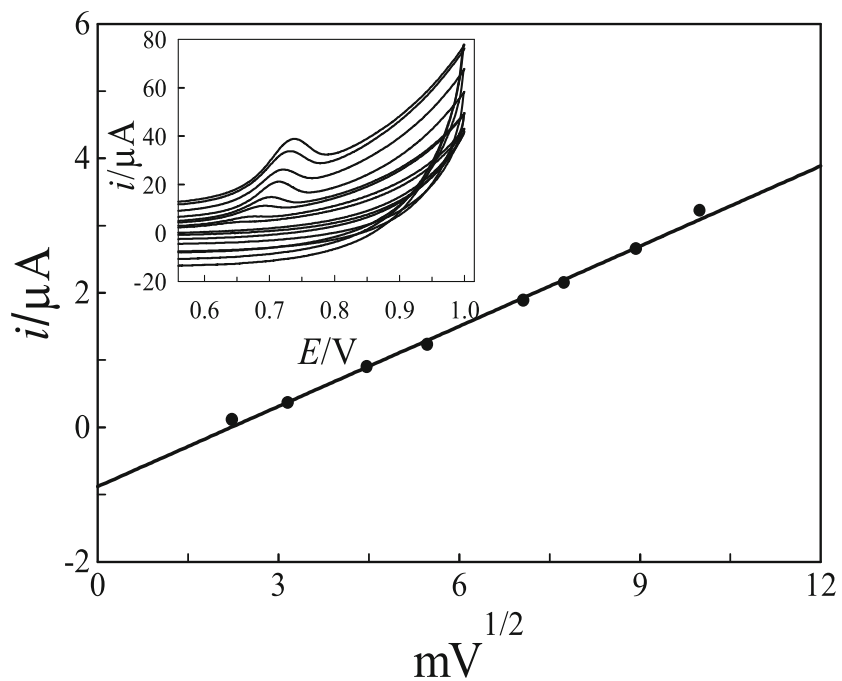

Fig. 5 Linear relationship of square root of scan rate versus oxidation current response of $10 \mu \mathrm{mol} / \mathrm{L}$ trp in $0.1 \mathrm{M}$ PBS (pH 5.5). Insert $\mathrm{CVs}$ of the $\mathrm{BMIMPF}_{6}-\mathrm{TiC} / \mathrm{GCE}$ at different scan rates (from 5 to $100 \mathrm{mV} / \mathrm{s}$ ) 


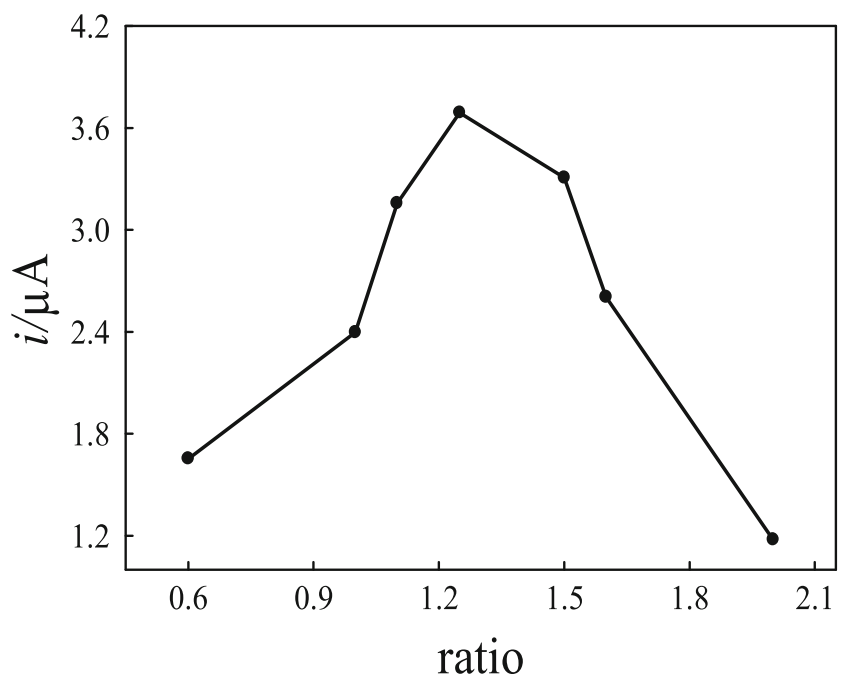

Fig. 6 Effect of the ratio of $\mathrm{TiC}$ nanoparticles in $\mathrm{BMIMPF}_{6}$ on the oxidation current response of $10 \mu \mathrm{mol} / \mathrm{L}$ trp in $0.1 \mathrm{M} \mathrm{PBS}(\mathrm{pH} 5.5)$ on $\mathrm{BMIMPF}_{6}-\mathrm{TiC} / \mathrm{GCE}$

trp. The effect of $\mathrm{pH}$ on the peak current of trp was investigated by recording DPV on $\mathrm{BMIMPF}_{6}-\mathrm{TiC}$ Gel/GCE of $10 \mu \mathrm{mol} / \mathrm{L}$ trp in $0.1 \mathrm{M}$ PBS of different $\mathrm{pH}$ ranging from 4.5 to 7.0 , and the results are displayed in Fig. 7a. The anodic peak current gradually increases from $\mathrm{pH} 4.5$ to $\mathrm{pH} 5.5$. The maximum current was observed at $\mathrm{pH}$ 5.5. However, the anodic peak current decreased when $\mathrm{pH}$ was further increased from $\mathrm{pH} 5.5$ to 7.0. Thus, $\mathrm{pH} 5.5$ was chosen. In addition, the peak potential shifted negatively and linearly as the solution $\mathrm{pH}$ increased from $\mathrm{pH} 4.5$ to 7.0 (Fig. 7b). The slope value of the $E p / \mathrm{pH}$ plots was $-52 \mathrm{mV} / \mathrm{pH}$, which implies that $\mathrm{H}^{+}$ transfer was involved in the electrode reaction. In the experiment, the relationship between the oxidation peak potentials and scan rates can be described as following: $E_{p a}=$ $0.049 \log v+0.8, r=0.999$. According to Laviron's theory, the slope was equal to $2.303 \mathrm{RT} / \mathrm{n}(1-\alpha) \mathrm{F}$. Then, the value of $n$ was

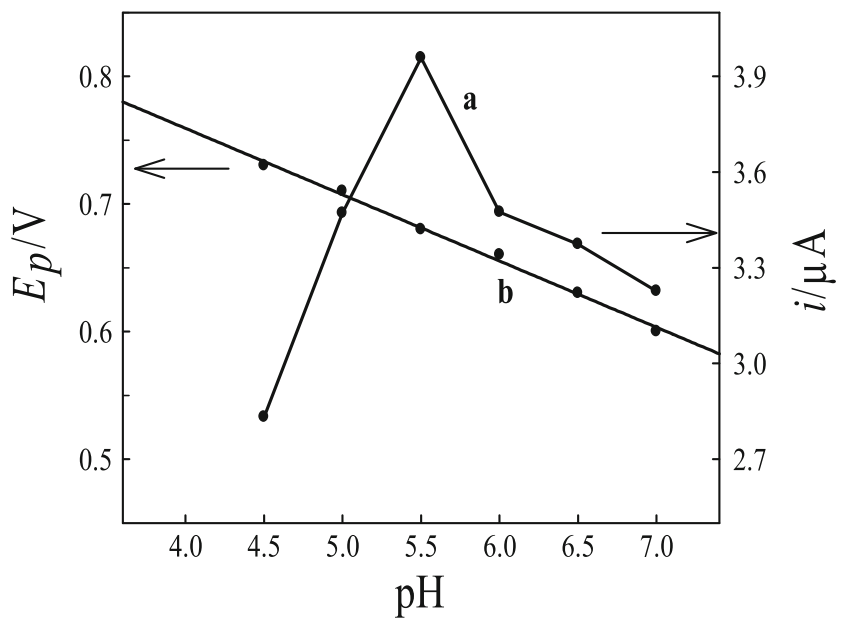

Fig. 7 Effect of $\mathrm{pH}$ on $\mathbf{a}$ the oxidation current response and $\mathbf{b}$ oxidation peak potential of $10 \mu \mathrm{mol} / \mathrm{L}$ trp in $0.1 \mathrm{M}$ PBS (pH 5.5) on $\mathrm{BMIMPF}_{6}$ $\mathrm{TiC} / \mathrm{GCE}$ calculated as 2.34. As for a totally irreversible electrode reaction process, $\alpha$ was assumed as 0.5 , which indicated that two electrons were involved in the oxidation process of trp at the gel modified electrode. Since equal numbers of electron and proton took part in the oxidation of trp, therefore the transfer of two electrons and two protons was involved in the electrode reaction process. The mechanism of the oxidation of trp at the gel modified electrode is shown in Scheme 2, which is in accordance with the report [80].

\section{Calibration curve}

The calibration curve of the trp determination was derived from the DPVs obtained on the $\mathrm{BMIMPF}_{6}-\mathrm{TiC} / \mathrm{GCE}$ in 0.1 M PBS ( $\mathrm{pH}$ 5.5) under the optimum conditions (Fig. 8). Two linear dynamic ranges as shown in Fig. 8 from 0.5 to $30 \mu \mathrm{mol} / \mathrm{L}$ and 30 to $500 \mu \mathrm{mol} / \mathrm{L}$ and a detection limit of $0.053 \mu \mathrm{mol} / \mathrm{L}$ were obtained. If the concentration of trp is less than the value of $30 \mu \mathrm{mol} / \mathrm{L}$, trp may be related to the formation of a monolayer on the surface of the modified electrode. However, if the concentration of trp is higher than the value of $30 \mu \mathrm{mol} / \mathrm{L}$, trp may be related to the formation of a multilayer on the surface of a modified electrode [81]. Meanwhile, the forces of the interaction were changed between trp and gel compound. So, the calibration curve plots of trp were broken at low and high concentrations. Linear regression equations for the two regions are as follows:

$I p(\mu \mathrm{A})=0.57+0.236 C(\mu \mathrm{mol} / \mathrm{L})(0.5-30 \mu \mathrm{mol} / \mathrm{L}, \mathrm{R}=0.9750)$



Fig. 8 The calibration curve for trp determination. Insert DPVs of the $\mathrm{BMIMPF}_{6}-\mathrm{TiC} / \mathrm{GCE}$ at different trp concentrations (from a 0.5 to $30 \mu \mathrm{mol} / \mathrm{L}$ and b 30 to $500 \mu \mathrm{mol} / \mathrm{L}$ ) in $0.1 \mathrm{M} \mathrm{PBS}$ (pH 5.5). Scan rate $50 \mathrm{mV} / \mathrm{s}$ 
Table 1 Comparison of response characteristic on different modified electrodes

\begin{tabular}{llll}
\hline Electrodes & Linear range $(\mu \mathrm{M})$ & Detecting limit $(\mu \mathrm{M})$ & References \\
\hline $\mathrm{BDD}^{\mathrm{a}}$ & $400-3000$ & 0.2 & 82 \\
$\mathrm{GNP}^{\mathrm{b}}-\mathrm{CNT}^{\mathrm{c}} / \mathrm{GCE}$ & $0.03-2.5$ & 0.01 & 69 \\
$\mathrm{GNP}_{\mathrm{CILE}}$ & $5-900$ & 1.2 & 83 \\
$\mathrm{GCE}$ modified with butyrylcholine & $2-60$ & 0.25 & 66 \\
Iron(III)-doped zeolite modified CPE & $0.2-150$ & 0.02 & 76 \\
$\mathrm{BMIMPF}_{6}$-TiC/GCE & $0.5-500$ & 0.053 & Present work \\
\hline
\end{tabular}

${ }^{\text {a }}$ Boron-doped diamond electrode

${ }^{\mathrm{b}}$ Gold nanoparticle

${ }^{\mathrm{c}}$ Carbon nanotube

${ }^{\mathrm{d}}$ Carbon ionic liquid electrode

${ }^{\mathrm{e}}$ Carbon paste electrode

$I p(\mu \mathrm{A})=6.72+0.025 C(\mu \mathrm{mol} / \mathrm{L})(30-500 \mu \mathrm{mol} / \mathrm{L}, \mathrm{R}=0.9983)$

fold ascorbic acid, histidine, aspartic acid, glycine, serine, 2fold dopamine, threonine, valine, phenylalanine did not affect the determination of $\operatorname{trp}(<5 \%$ of response current change).

The response characteristics of the $\mathrm{BMIMPF}_{6}$ - $\mathrm{TiC} / \mathrm{GCE}$ were compared with those in previously published works. As shown in Table 1, the proposed BMIMPF ${ }_{6}$-TiC/GCE had wider linear dynamic range and lower detection limit than most of the materials used in other works for trp determination.

Reproducibility, repeatability, and selectivity

The reproducibility of $\mathrm{BMIMPF}_{6}-\mathrm{TiC} / \mathrm{GCE}$ was investigated by detecting a certain amount of trp in $0.1 \mathrm{M} \mathrm{PBS}(\mathrm{pH} 5.5)$ for one electrode in ten measurements. The relative standard deviation (RSD) of the anodic peak current was $2.8 \%$ for trp determination. The repeatability of the developed method was also evaluated by using five different $\mathrm{BMIMPF}_{6}-\mathrm{TiC} /$ GCEs, and the obtained RSD was $2.9 \%$. Therefore, BMIMPF $_{6}-\mathrm{TiC} / \mathrm{GCE}$ showed good reproducibility and repeatability.

The selectivity of the $\mathrm{BMIMPF}_{6}$-TiC/GCE for the trp determination was investigated by adding various foreign species into PBS (pH 5.5) containing $10 \mu \mathrm{mol} / \mathrm{L}$ trp. Moreover, 500-fold $\mathrm{Na}^{+}, \mathrm{K}^{+}, \mathrm{NO}_{3}{ }^{-}$, 150-fold lactose, 100-fold urea, sucrose, $\mathrm{Mg}^{2+}, \mathrm{SO}_{4}{ }^{2-}, \mathrm{Ca}^{2+}, 50$-fold glucose, fructose, 5-

Table 2 Results of real sample analysis at $\mathrm{BMIMPF}_{6}-\mathrm{TiC} / \mathrm{GCE}$

\begin{tabular}{llll}
\hline Real samples & Trp added $(\mu \mathrm{M})$ & Trp found $(\mu \mathrm{M})$ & Recovery $(\%)$ \\
\hline Milk & 5.0 & $5.16 \pm 0.024$ & 103.2 \\
& 10.0 & $10.61 \pm 0.042$ & 106.1 \\
\multirow{2}{*}{ Urine } & 15.0 & $15.66 \pm 0.033$ & 104.4 \\
& 5.0 & $5.28 \pm 0.040$ & 105.7 \\
& 10.0 & $10.73 \pm 0.047$ & 107.3 \\
& 15.0 & $15.54 \pm 0.063$ & 103.6 \\
\hline
\end{tabular}
electrode.

\section{Practical application of $\mathrm{BMIMPF}_{6}-\mathrm{TiC} / \mathrm{GCE}$}

The practical utility of $\mathrm{BMIMPF}_{6}-\mathrm{TiC} / \mathrm{GCE}$ was evaluated by employing it for the determination of trp in the human urine and cow's milk. The concentration of trp was estimated by standard addition method. The amperometric response of trp was recorded at $\mathrm{BMIMPF}_{6}-\mathrm{TiC} / \mathrm{GCE}$, and the results are displayed in Table 2. From the good quantitative recoveries and precision of the results observed, $\mathrm{BMIMPF}_{6}-\mathrm{TiC} / \mathrm{GCE}$ can be successfully employed for the determination of trp in real samples. The present method is reliable and suitable for the determination of trp in food and biological samples.

\section{Conclusions}

In this work, a simple and effective method for the quantification of trp by modifying the GCE with $\mathrm{BMIMPF}_{6}-\mathrm{TiC}$ gel was used. SEM and EDX results demonstrated that $\mathrm{BMIMPF}_{6}$ and $\mathrm{TiC}$ nanoparticles were successfully doped into the GCE. Compared with bare GCE, the obtained $\mathrm{BMIMPF}_{6}-\mathrm{TiC} / \mathrm{GCE}$ exhibited significantly enhanced electrocatalytic performance in trp determination. The detection limit of trp was $0.053 \mu \mathrm{mol} / \mathrm{L}$. In addition, the $\mathrm{BMIMPF}_{6}-\mathrm{TiC} / \mathrm{GCE}$ showed excellent reproducibility, repeatability, and selectivity and can be applied for determination in real samples. The fabricated electrode may serve as an electrochemical sensor for high sensitive trp determination. This work provides a simple and easy approach to selectively detect trp and had wider linear dynamic range and lower detection limit. It showed good 
reproducibility and repeatability and had good antiinterference ability. BMIMPF ${ }_{6}-\mathrm{TiC} / \mathrm{GCE}$ can be successfully employed for the determination of $\operatorname{trp}$ in real samples.

Acknowledgments This work was financially supported by the National Natural Science Foundation of China (41276093 and 21275091), the Youth Innovation Promotion Association and Outstanding Young Scientists of CAS.

\section{References}

1. Gupta VK, Manglar R, Khurana U, Kumar P (1999) Electroanalysis 11:573-576

2. Gupta VK, Ganjali MR, Norouzi P, Khani H, Nayak A, Agarwal S (2011) Crit Rev Anal Chem 41:282-313

3. Gupta VK, Chandra S, Mangla R (2002) Electrochim Acta 47:15791586

4. Jain AK, Gupta VK, Singh LP, Raisoni JR (2006) Electrochim Acta $51: 2547-2553$

5. Gupta VK, Prasad R, Kumar A (2003) Talanta 60:149-160

6. Gupta VK, Chandra S, Lang H (2005) Talanta 66:575-580

7. Strivastava SK, Gupta VK, Jain S (1996) Anal Chem 68:1272-1275

8. Gupta VK, Jain AK, Kumar P, Agarwal S, Maheshwari G (2006) Sensor Actuat B-Chem 113:182-186

9. Gupta VK, Jain AK, Maheshwari G, Lang H, Ishtaiwi Z (2006) Sensor Actuat B-Chem 117:99-106

10. Gupta VK, Jain AK, Kumar P (2006) Sensor Actuat B-Chem 120: 259-265

11. Jain AK, Gupta VK, Singh LP, Khurana U (1997) Analyst 122:583586

12. Gupta VK, Singh LP, Singh R, Upadhyay N, Kaur SP, Sethi B (2012) J Mol Liq 174:11-16

13. Gupta VK, Sethi B, Sharma RA, Agarwal S, Arvind B (2013) J Mol Liq 177:114-118

14. Gupta VK, Prasad R, Kumar P, Mangla R (2000) Anal Chim Acta 420:19-27

15. Gupta VK, Jain S, Chandra S (2003) Anal Chim Acta 486:199-207

16. Prasad R, Gupta VK, Kumar A (2004) Anal Chim Acta 508:61-70

17. Gupta VK, Singh AK, Mehtab S, Gupta B (2006) Anal Chim Acta 566:5-10

18. Gupta VK, Singh AK, Khayat MA, Gupta B (2007) Anal Chim Acta 590:81-90

19. Gupta VK, Jain S, Khurana U (1997) Electroanalysis 9:478-480

20. Gupta VK, Nayak A, Agarwal S, Singhal B (2011) Comb Chem High Throughpat Scr 14:284-302

21. Goyal RN, Gupta VK, Chatterjee S (2008) Electrochim Acta 53: 5354-5360

22. Gupta VK, Jain R, Radhapyari K, Jadon N, Agarwal S (2011) Anal Biochem 408:179-196

23. Zhao F, Wu XE, Wang MK (2004) Anal Chem 76:4960-4967

24. Pernak J, Czepukowicz A, Pozniak R (2001) Ind Eng Chem Res 40: 2379-2383

25. Safavi A, Ahmadi R, Mahyari FA (2014) Amino Acids 46:10791085

26. Eslami E, Farjami F, Aberoomand Azar P (2014) Electroanalysis 26: 424-431

27. Afkhami A, Khoshsafar H, Bagheri H, Madrakian T (2014) Mat Sci Eng C-Mater 35:8-14

28. Zhao LF, Wei Q, Wu H, Dou JK, Li H (2014) Biosens Bioelectron 59:75-80

29. Arkana E, Saber R, Karimi Z, Mostafaie A, Shamsipur M (2014) J Pharm Biomed Sci 92:74-81
30. Sanchez A, Morante-Zarcero S, Perez-Quintanilla D, Sierra I, del Hierro I (2010) Electrochim Acta 55:6983-6990

31. Han L, Hang XL (2009) Electroanalysis 21:124-129

32. Chu L, Zhang XL (2012) J Electroanal Chem 665:26-32

33. Raoof JB, Ojani R, Baghayeri M (2009) Sensor Actuat B-Chem 143: 261-269

34. Goyal RN, Gupta VK, Bachheti N, Sharma RA (2008) Electroanalysis 20:757-764

35. Goyal RN, Gupta VK, Chatterjee S (2008) Talanta 76:662-668

36. Goyal RN, Gupta VK, Bachheti N (2007) Anal Chim Acta 597:8289

37. Bijad M, Karimi-Maleh H, Khalilzadeh MA (2013) Food Anal Method 6:1639-1647

38. Vahedi J, Karimi-Maleh H, Baghayeri M, Sanati AL, Khalilzadeh MA, Bahrami M (2013) Ionics 19:1907-1914

39. Fouladgar M, Karimi-Maleh H (2013) Ionics 19:1163-1170

40. Sanati AL, Karimi-Maleh H, Badiei A, Biparva P, Ensafi AA (2014) Mat Sci Eng C-Mater 35:379-385

41. Pahlavan A, Karimi-Maleh H, Karimi F, Amiri MA, Khoshnama Z, Shahmiri MR, Keyvanfard M (2014) Sci Eng C-Mater 45:210-215

42. Jamali T, Karimi-Maleh H, Khalilzadeh MA (2014) Lwt-Food Sci Technol 57:679-685

43. Elyasi M, Khalilzadeh MA, Karimi-Maleh H (2013) Food Chem $141: 4311-4317$

44. Naiafi M, Khafilzadeh MA, Karimi-Maleh H (2014) Food Chem 158:125-131

45. Tavana T, Khalilzadeh MA, Karimi-Maleh H, Ensafi AA, Beitollahi H, Zareyee D (2012) J Mol Liq 168:69-74

46. Beitollah H, Goodarzian M, Khalilzadeh MA, Karimi-Maleh H, Hassanzadeh M, Tajbakhsh M (2012) J Mol Liq 173:137-143

47. Karimi-Maleh H, Sanati AL, Gupta VK, Yoosefian M, Asif M, Bahari A (2014) Sensor Actuat B-Chem 204:647-654

48. Zhang DW, Li J, Zheng JB (2013) Mater Lett 93:99-102

49. Kutlan D, Molnar-Perl I (2003) J Chromatogr A 987:311-322

50. Yust MM, Pedroche J, Giron-Calle J, Vioque J, Millan F, Alaiz M (2004) Food Chem 85:317-320

51. Trucksess MW (1993) J Chromatogr A 630:147-150

52. You JM, Shan YC, Zhen L, Zhang L, Zhang YK (2003) Anal Biochem 313:17-27

53. Swann LM, Forbes SL, Lewis SW (2010) Talanta 81:1697-1702

54. Arvidsson B, Johannesson N, Citterio A, Righetti PG (2007) J Chromatogr A 1159:154-158

55. Lee GH, Choi OK, Jung HS, Kim KR, Chung DS (2000) Electrophoresis 21:930-934

56. Altria KD, Harkin P, Hindson MG (1996) J Chromatogr B 686:103110

57. Jin WR, Li XJ, Gao N (2003) Anal Chem 75:3859-3864

58. Sikorska E, Glisuzynska-Swiglo A, Insinska-Rak M, Khmelinskii I, De Keukeleire D, Sikorski M (2008) Anal Chim Acta 613:207-217

59. Lin ZJ, Chen XM, Cai ZM, Li PW, Chen X, Wang XR (2008) Talanta 75:544-550

60. Hanaoka S, Lin JM, Yamada M (2000) Anal Chim Acta 409:65-73

61. Pollet E, Martínez JA, Metha B, Watts BP, Turrens JF (1998) Arch Biochem Biophys 349:74-80

62. Sakura S (1992) Electrochim Acta 37:2731-2735

63. Costin JW, Francis PS, Lewis SW (2003) Anal Chim Acta 480:67-77

64. Mizdrak J, Hains PG, Truscott RGW, Jamie JF, Davies MJ (2008) Free Radic Biol Med 44:1108-1119

65. MacDonald SM, Roscoe SG (1997) Electrochim Acta 42:1189-1200

66. Jin GP, Lin XQ (2004) Electrochem Commun 6:454-460

67. Nan CG, Feng CC, Li WX, Ping DG, Qin CH (2002) Anal Chim Acta 452:245-254

68. Frith KA, Limson JL (2010) Electrochim Acta 55:4281-4286

69. Guo YJ, Guo SJ, Fang YX, Dong SJ (2010) Electrochim Acta 55: 3927-3931 
70. Fang B, Wei Y, Li MG, Wang GF, Zhang W (2007) Talanta 72:13021306

71. Huang KJ, Xu CX, Xie WZ, Wang W (2009) Colloid Surface B 74: $167-171$

72. Raoof JB, Ojani R, Amiri-Aref M, Baghayeri M (2010) Sensor Actuat B-Chem 143:261-269

73. Tang XF, Liu Y, Hou HQ, You TY (2010) Talanta 80:2182-2186

74. Raoof JB, Ojani R, Karimi-Maleh H (2008) Electroanalysis 20:1259-1262

75. Jin GP, Peng X, Chen QZ (2008) Electroanalysis 20:907-915

76. Babaei A, Zendehdel M, Khalilzadeh B, Taheri A (2008) Colloid Surface B 66:226-232
77. Li CY, Ya Y, Zhan GQ (2010) Colloid Surface B 76:340-345

78. Shahrokhian S, Fotouhi L (2007) Sensor Actuat B-Chem 123:942949

79. Yu Q, Liu Y, Liu XY, Zeng XD, Luo SL, Wei WZ (2010) Electroanalysis 22:1012-1018

80. Liu X, Luo LQ, Ding YP, Ye DX (2011) Bioelectrochemistry 82:3845

81. Liu HH, Chen YL, Liu YC, Yang ZS (2013) J Solid State Electrochem 17:2623-2631

82. Zhao ZH, Qi Y, Tian Y (2006) Electroanalysis 18:830-834

83. Safavi A, Momeni S (2010) Electroanalysis 22:2848-2855 